\title{
Two Different Shapes of Insulin Microparticles Produced by Solution Enhanced Dispersion Supercritical Fluid (SEDS) Process
}

\author{
Dongjin Pyo \\ Department of Chemistry Kangwon National Lnversitv, Chunchon 200-701, Korea. E-mail: pvodakangwon.ac.kr \\ Received February 18, 2009. Accepted March 25, 2009
}

Key Words: Microparticle. Supercritical fluid. Insulin

The administration of drugs to the lung via inhalation is a promising altemative to injection or oral administration. Small micro-particles with a narrow particle size distribution are desirable for applications in pulmonary delivery and controlled release systems. ${ }^{\text {l.- }}$ In the case of protein drug administration through the lung by way of inhalation. the small particle size is especially important. because not only particles larger than $5, a \mathrm{~m}$ tend to fall out of the gas stream and deposit in the mucosa of the upper airway's before reaching the alveoli of the lungs but incompletely dissolved protein particles can cause undesired side effects such as inflammation or immune response against the drug protein itself. Pulmonary delivery of a protein drug can avoid the hepatic first-pass effect of and the digestive process typical for an oral administration as well as the discomfort of the needle injection associated with a parenteral one. A good example where such pulmonary delivery can significantly improve the patient's comfort is the insulin inhalation therapy for diabetics. an issue which has already been investigated in clinical studies. ${ }^{3}$ Formulation technology developed for manufacturing microparticles of a protein dnıg for a pulmonary delivery șystem. in addition, has a far reaching potential as a general tool for developing protein dnig formulations that enable hitherto unrealized applications such as an oral or topical delivery of protein drugs with or without controlled release features. In many cases. sustained release formulations of dnigs are desirable in order to alleviate immediate concentration bursts of the therapeutic agents.

Insulin is a peptide hormone composed of 51 amino acid residues and has a molecular weight of $5808 \mathrm{Da}$. It is produced in the Islets of Langerhans in the pancreas.

It consists of two chains, A ( 21 residues) and B ( 30 residues) and is the post translational product of a single chain precursor. namely pro-insulin. which possesses an extra linking peptide of varying lengths depending on the species. The three disulphide bonds are essential in maintaining the folding and stability of the protein.

Proteins such as insulin are often prone to denaturation or degradation if exposed to a high temperature. Therefore. their micronization through mechanical comminution or milling is almost impossible since these processes generally produce heat raising temperature significantly above the ambient temperature. Furthermore, milling or grinding often results in electrostatically charged particles with rather a broad particle size distribution. Thus conventional and commonly used nondestructive processes for producing protein powder has relied on lyophilization. spray drying crystallization. or precipitation from a target protein solution. Protein crystallization may be induced by applying a temperature gradient. by the addition of a liquid anti-solvent, or by adjusting the $\mathrm{pH}$ value of the solution to the isoelectric point of the protein. All of these processes. however, suffer from various drawbacks. Spray drying may often induce denaturation of the proteins and thus entail low yields. Lyophilization often produces protein particles that are not snall enough for either pulmonary delivery or encapsulation into controlled release microspheres. ${ }^{+}$Other processes necessitate employment of large amounts of organic solvents and subsequent downstream separation and recovery steps of the solvents. Moreover, these processes may also lead to high residual solvent contents in the resultant protein powders.

Particle formation tecluniques based upon the use of nearor supercritical fluids are an interesting alternative to the processes mentioned above as they overcone most of the drawbacks of conventional particle size reduction techniques and allow, at the same time, production of submicron-particles with controlled particle size distributions under mild and inert conditions. This is particularly the case when nontoxic. low cost carbon dioxide is used as near-critical fluid solvent or anti-solvent $\left(\mathrm{T}_{c}=31 . \mathrm{I}^{\circ} \mathrm{C} . \mathrm{P}_{\mathrm{c}}=73.8 \mathrm{bar}\right)$. In the rapid expansion of supercritical solutions (RESS) process, supercritical $\mathrm{CO}_{2}$ is used as a solvent to achieve particle formation by expanding binary mixtures of solvent and solute across capillary or ultrasonic nozzles. The application of RESS to protein precipitation is hindered by the drastically low solubility of proteins of practical interest in ligh pressure carbon dioxide. Anti-solvent tecluniques. on the other hand. make use of the low solubility of most proteins and many pharmaceutical compounds in $\mathrm{CO}_{2}$ In fact, $\mathrm{CO}_{2}$ is used as an anti-solvent for the solute, which is initially soluble in a conventional organic solvent that is conpletely miscible with carbon dioxide. Upon carbon dioxide addition to the initial solution. the solute precipitates due to reduced solubility in $\mathrm{CO}_{2}$. Carbon dioxide and the solution can be brought into contact in different ways. namely by either gradually adding compressed carbon dioxide to the solution, or by spraying the solution into a vessel initially pressurized with carbon dioxide. The latter alternative. referred to as the solution enhanced dispersion by supercritical fluids (SEDS), was used in this study to precipitate insulin proteins from modified aqueous solutions. ${ }^{5}$ Proposed 
by York and coworkers. this method could produce spherical precipitates of ly'sozyme or trypsin with mean particle sizes below $1 \mu \mathrm{m}$ from their respective aqueous solutions. where dimethyl sulfoxide was used as a secondary modifier solvent. ${ }^{5}$ In another stidy. fairly large agglomerates consisting of primary particles of mean diameters between 1 and $5 \mu$ m were obtained through precipitation of lysoz'me from DMSO and those retained biological activities between 50 and $100 \%$ depending on the choice of operating conditions. ${ }^{6}$ A SEDS process has also been applied to the precipitation of an aqueous formulation of recombinant human immunoglobin $\mathrm{G}$ using carbon dioxide with dimethyl sulfoxide as a modified supercritical fluid anti-solvent.

Sievers and coworkers consistently obtained particles of various pharmaceutical agents. peptides and proteins. with mean particle sizes in the range of $0.1-3 \mu \mathrm{m}$, from their respective aqueous solutions through rapid decompression of emulsions formed by mixing the solutions with carbon dioxide. ${ }^{89}$ Product particle sizes and their distributions could be controlled to some extent by varying concentration of the protein solution. Again. no significant loss of protein activity after the $\mathrm{CO}_{2}$ assisted nebulization process has been observed.

In this paper. we report that two different shapes of insulin microparticles produced by changing polar solvents with SEDS process. When ethanol was used, rod shapes of insulin particles were produced and when dimethyl sulfoxide was used spherical shapes of insulin particles were produced. These phenomena have never been reported in the literatures.

\section{Experimental}

Apparatus. Fig. 1 is the schematic diagram of the continuous SEDS apparatus used in the present study. It consists of three main parts: feeding. precipitation and particle collection units. An HPLC pump (model: SYSTEM- GOLD Programmable Solvent Module 126. Beckman. USA) was used to deliver insulin solution and another high pressure

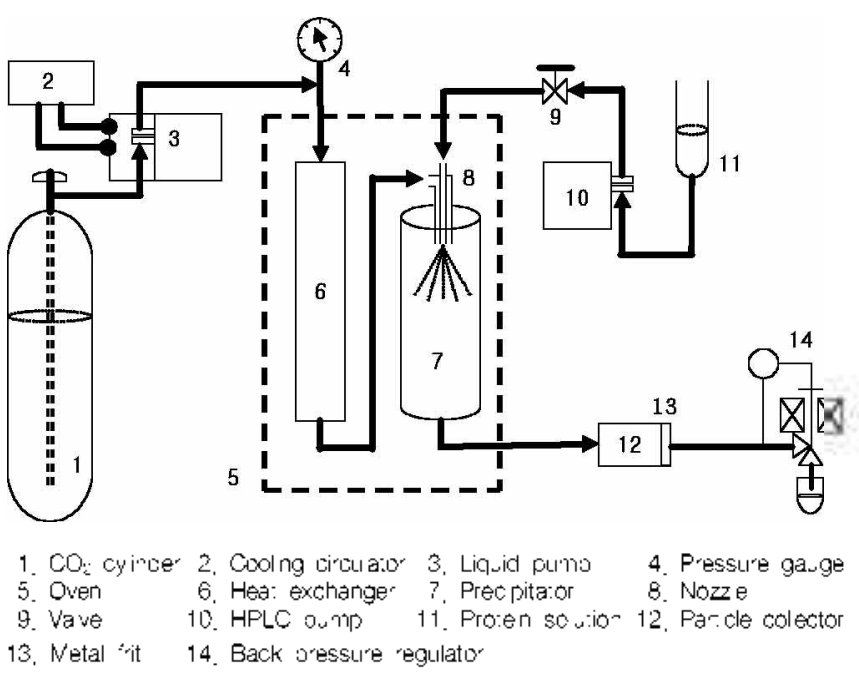

Figure 1. Schematic diagram of particle formation apparatus with a continuous Solution Enhanced Dispersion of Supercritical tluid (SEDS) process. liquid pump (model: NS-500. Nihon Seinitsu, Japan), for carbon dioxide. Through a coaxial injection tube. carbon dioxide and insulin solution were diverted. respectively into the precipitator. The precipitator is a stainless steel chamber (JASCO. Japan) with an inside diameter of $20 \mathrm{~mm}$. a length of $250 \mathrm{~mm}$. and an internal volume of $78.5 \mathrm{~cm}^{3}$. The coaxial injector comprised a $3.175 \mathrm{~mm}$ (OD). $2.135 \mathrm{~mm}$ (ID) stainless steel tube with a commercially available. $1.587 \mathrm{~mm}$ (OD), 0.508 num (ID) PEEK capillary tube insert. While insulin solution was being sprayed into the chamber via the capillary tube, carbon dioxide was charged simultaneously through the stainless steel tube (outside the capillary tube). A 0.2 um metal frit was mounted at the particle collector to retain protein particles. The precipitator was immersed in a themnostatic oven. which was regulated to within $\pm 0.1 \mathrm{~K}$. A pressure transducer (model: 312 SS, ranging $0-10000$ psi, WIKA, USA) measured the operation pressure in the precipitator.

The experimental procedure is described as follows. At a given bath temperature, the mass flow rate of carbon dioxide was adjusted to about $30 \mathrm{~mL} / \mathrm{min}$ during each precipitator nun and the precipitator was maintained at a constant pressure by manipulating the liquid pump and the needle valve at the back pressure regulator (nodel : $880-81$, JASCO. Japan). While keeping a steady-state with the influx of $\mathrm{CO}_{2}$. the protein solution was introduced into the precipitation chamber via the capillary Teflon tube at a pre-specified flow rate. Upon the droplet of protein solution contacting supercritical carbon dioxide in the precipitator, the solvent vaporizes instantaneously into the carbon dioxide rich phase and the protein particles form due to the supersaturation of the solute. Even after the period of particle formation. the flow of carbon dioxide was maintained for about $1-1.5 \mathrm{~h}$ to remove the residual solvent inside the precipitator. The precipitation chamber was then depressurized gradually to atmospheric pressure. The collected samples at different positions, including the sample on the metal frit. were collected from the chamber and observed with a field emission scanning electron microscope (FESEM) (model: \$-4300. HITACHI. Japan).

Matelial. Dimethỵl sulfoxide (purity 99.9\%), ethanol (purity 99.9\%) and water (purity $99.9 \%$ ) were HPLC grade and were bought from Aldrich (Milwaukee. WI). The insulin was supplied by Regeron. Inc. (Chunchon, Korea). $\mathrm{CO}_{2}$ (purity 99.9\%) was supplied by Gold-star Oxygen Ltd. (ChunChon. Korea)

\section{Results \& Discussion}

To make insulin micro-particles with supercritical fluid. we enployed the solution-enlanced dispersion (SEDS) technique in this study. The microparticle formation of heat labile proteins. such as insulin. is difficult to achieve by conventional high temperature drying teclniques. SEDS process uses an additional polar solvent to help the supercritical carbon dioxide to extract water from the aqueous protein solution. For this reason. ethanol was used as an additional polar solvent. Ethanol also helped insulin protein miroparticles to improve on their dissolution rate in water. The SEM photograph of insulin particles obtained with aqueous 


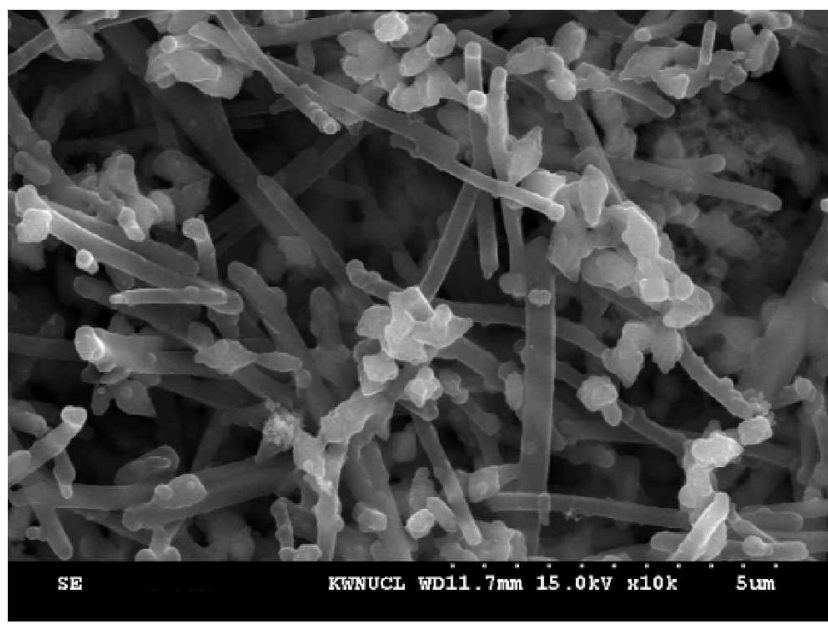

Figure 2. FE-SEM image of insulin microparticles with ethanol. Esperinental conditions : $40{ }^{\circ} \mathrm{C}, 100$ bar, flow rate of carbon dioxide $20 \mathrm{~mL} / \mathrm{min}$, flow rate of $95 \%$ ethanol solution $0.6 \mathrm{~mL} / \mathrm{min}$.

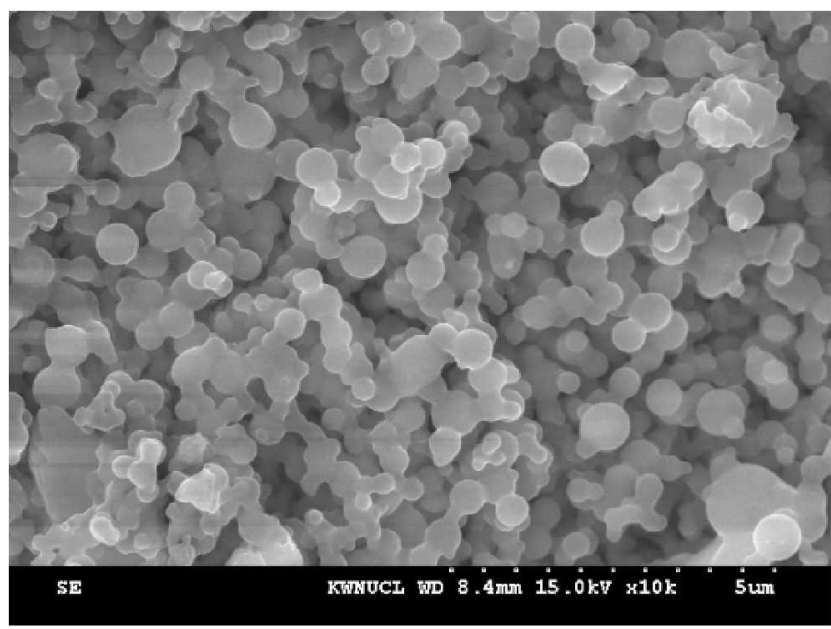

Figure 3. FE-SEM image of insulin microparticles with dimethylsulfoxide. Experimental conditions: $40^{\circ} \mathrm{C}, 100 \mathrm{bar}$, flow rate of carbon dioxide $20 \mathrm{~mL} / \mathrm{min}$, flow rate of $95 \%$ dimethylsultoxide solution $0.6 \mathrm{~mL} / \mathrm{min}$

ethanol solution is presented in Fig. 2. Fig. 2 shows insulin micro-particles in rod shapes with a mean length of about $5 / \mathrm{mm}$ that was prepared from aqueous ethanol solution. However. when dimethyl sulfoxide was used as an additional polar solvent. surprisingly. spherical shapes of insulin microparticles were produced (Fig. 3). The dramatic change from a rod shape to a spherical shape is a new finding in this paper which has never been reported in the literatures. In Fig. 3, the shapes of insulin microparticles are not totally spherical and microparticles stick to each other. The reasons of these phenomena result from the moisture remaining in microparicles. For the future. we are going to develop the method to eliminate the moisture remaining in insulin microparticles.

Although the potential of SEDS process in manufacturing protein microparticles has been recognized and successfully realized, very little is known about the nature of the process that enables the particle size prediction for each system. partly due to complexity of the process parameters. Hydrody namics. phase behavior and crystallization thermodynamics of the system change throughout the process and all need to be considered simultaneously. The parameters that may influence the shapes of the particles precipitated by the SEDS process include the nature of the solvent. solution concentration, operating temperature and pressure. flow rates of the solution and $\mathrm{CO}_{2}$. and the type and size of the nozzle used for spraying. At the present day, we do not fully understand how two different shapes of insulin microparticles were produced. For the reasons of precipitation of insulin particles with different shapes. we only deduce that the droplet shapes from the nozzle would be different due to the difference in interfacial tensions of ethanol and dimethyl sulfoxide solutions. When droplets are produced in a precipitation vessel. the droplet size and size distribution depend on the interfacial tension of the droplet. Interfacial properties have a fundamental influence on dense gas/liquid separation processes, with the interfacial tension being an important parameter associated with mass transfer.

It is known ${ }^{10}$ that the efficiency of SEDS microparticle formation system is deternined by droplets size produced in the nozzle and by the manner in which the supercritical medium mixes with the droplets. A nozzle is a device that renders liquid to disintegrate into droplets of a specified size range and controls their spatial distribution. Droplet sizes are correlated with individual system dimension as well as the ratio of the flow of the supercritical fluid to that of the solution.

In conclusion insulin microparticles were produced successfully from ethanol and dimethyl sulfoxide solution using supercritical carbon dioxide as an anti-solvent. We used ethanol and dimethyl sulfoxide to help the supercritical carbon dioxide to extract water from the aqueous protein solution. Two different shapes of insulin microparticles were produced by SEDS Process. When ethanol was used. rod shapes of insulin particles were produced and when dinethyl sulfoxide was used. spherical shapes of insulin particles were produced.

\section{Refeiences}

1. Kompella, U. B.: Koushik, K. Critical Reviews in Therapentic Drug Camier ststents 2001, 18, 173

2. Debenedetti, P. G.; Tom, J. W: Yeo, S. D.; Lim, G. B. Joumal of Controlled Release 1993, 24, 27.

3. Laube, B. L.: Georgopoulos, A.: Adams, G. K. Jommal of the American Medical Association 1993, 269, 2106.

4. Tom, T. W: Lim, G. B.: Debenedetti, P. G.; Prud homme, R. K. Supercritical fluid engineening science and technologv, ACS Symposium Series: Washington DC. USA, 1993.

5. Sloan, R: Hollowood, M. E: Humphreys, G. O; Ashraf, W: York P. Supercritcal fuids in proceedings of the 5 th nteeting, 1998; 301

6. Moshashae, S.; Bisrat, M.: Forbes, R. T.: Nyquist, H.: York, P. Enopean Joumal of Phamacentical Sciences 2000, 11, 239.

7. Nesta, D. P.; Elliott, T. S.; Warr, T. P. Biotechology and Bioenginesting $\mathbf{2 0 0 0}, 67,457$

8. Sievers, R. E.; Karst, U.: Milewski, P. D.: Sellers S. P.: Miles, B. A.: Schater, I. D.: Stoldt, C. R.; Xu, C. Y. terosol Science and Technology $1999,30,3$

9. Sellers, S. P.; Clark, G. S.; Sievers, R. E.; Carpenter, J. F. Joumal of Phamacentical Sciences 2001, 90,785.

10. Pyo, D.: Lim, C.: Cho, D.: Oh. D. Anahtical and Bioanalvical Chemism 2007, 387,901 